REsumo
Discute-se um caso clínico priori-
zando algo que se manifesta em
adolescentes como um mau com-
portamento e que a psiquiatria
denomina transtorno de conduta.
Mas que aqui dirá respeito a
uma ação impulsiva, irrefreável,
disruptiva, que se aproxima
do acting out e da passagem
ao ato, descritos por Lacan em
$1962-1963$ no Seminário 10:
a angústia. Com essa discussão,
será possível afirmar que essas
ações são respostas diante da
inconsistência do Outro epropor
uma direção de tratamento para
esses casos.
Descritores: adolescência;
acting out; passagem ao ato;
psicanálise lacaniana.

\section{O ADOLESCENTE E A INCONSISTÊNCIA DO OUTRO: DISCUSSÃO SOBRE A DIREÇÃO DE TRATAMENTO A PARTIR DE CASO CLÍNICO'}

\author{
Mirela Stenzel \\ Vinicius Anciães Darriba
}

N

este artigo pretende-se trazer uma discussão de caso a partir de clínica desenvolvida com adolescentes em ambulatório infanto-juvenil de saúde mental, priorizando determinadas ações que se manifestam no comportamento de adolescentes. Tais ações são reportáveis a fenômenos que a psiquiatria, no DSM-IV (Diagnostic and Statistical Manual of Mental Disorders) e no CID-10 (Código Internacional das Doenças), denomina transtorno de conduta. Suspendendo a categorização psiquiátrica, o que verificamos é uma ação impulsiva, irrefreável, disruptiva, quanto à qual o adolescente tem muito pouco a dizer, e que será aproximada do acting out e da passagem ao ato, tal como descritos por Lacan (2005). Tal discussão tomará essas ações como respostas possíveis diante da inconsistência do Outro e proporá uma direção de tratamento para esses casos.

- Psicóloga. Mestre em Psicologia pela Universidade Federal do Paraná (UFPR), Curitiba, PR. Brasil. 


\section{O caso clínico}

Trata-se de um adolescente de 15 anos com sérias dificuldades escolares, cursando a quinta série há quatro anos. Havia queixas de mau comportamento: brigas com colegas, desrespeito com os professores e depredação. Gazeteia aulas e, por fim, colocou fogo numa lixeira. Também ocorreram fugas de casa, que deixaram os pais muito preocupados. $\mathrm{O}$ adolescente sempre negava as queixas do colégio e dos pais. Trazia desculpas para o comportamento ou dizia que era outro adolescente, o quel possuía o mesmo nome que ele. Dizia ser perseguido pelos professores: "tudo o que acontece na escola de errado fui eu".

Por um lado, havia uma grande dificuldade do adolescente de se manter em um propósito adequado socialmente, numa boa produção escolar, num bom comportamento, e, por outro lado, havia essa tendência a ações que se inseriam numa agitação motora, em atitudes antissociais, nas brigas, na falta de respeito com os professores.

As queixas dos pais sobre o comportamento em casa estavam relacionadas às fugas, que eles atribuíam a uma depressão e, também, ao relacionamento conflituoso do adolescente com a irmã, que recebia proteção do pai. Quando os filhos brigavam o pai a defendia, enquanto a mãe se colocava do lado do adolescente diante de uma suposta injustiça do pai: "meu pai sempre acha que minha irmã não faz nada, tudo fui eu...”. O pai era segurança, mas estava afastado por ter se machucado. Ficava em casa, cumpria algumas tarefas caseiras e jogava videogame, enquanto a mãe ia trabalhar.

As fugas ocorreriam quando os pais se mostravam não só bravos com os comportamentos do adolescente, mas decepcionados. Depois de um tempo notavam que o adolescente não estava em casa. Passavam a procurá-lo pela vizinhança. Algumas vezes o encontravam rapidamente, mas no último episódio o encontraram dois dias depois vagando pelas ruas da cidade. Quando era questionado pelos pais sobre o que fez durante o tempo em que ficou fora, ou por que havia feito aquilo, o adolescente não tinha resposta a dar. Da mesma forma, nos atendimentos, não conseguia nem sequer relatar o que havia acontecido e dizia com certo mal-estar: "Não sei o que 
passava pela minha cabeça".

Durante o tratamento, ficou clara a seguinte dinâmica: depois que os pais eram chamados à escola em razão de alguma ação do adolescente, este se propunha a melhorar, mantinha-se em um comportamento adequado, cumprindo as obrigações escolares. Até que em um determinado momento, irrompiam novas ações, assim se repetindo a dinâmica.

A analista acabou colocando-se nessa dinâmica, na medida em que os pais traziam os fatos, como se pudesse reforçar a necessidade do adolescente em se manter no bom propósito. Quando conseguiu perceber essa dinâmica, apontou isso aos pais e ao adolescente, e passou, na direção do tratamento, a apontar para o desejo. As intervenções, anteriormente, acabavam por buscar o bem do paciente, um bom comportamento.

O adolescente sempre estava na defensiva, pronto para se desresponsabilizar por suas ações, parecia ter muita dificuldade em trazer pela via da palavra o que lhe ocorria. Seus relatos eram sucintos e pobres. Dizia pouco sobre o que acontecia, e em geral surgia um desconforto e ditos como "Não consigo", "Sou hiperativo". Começou, no entanto, a trazer as trocas que fazia, as vantagens que levava ou desvantagens; fazia "rolo". Assim, trocou cinquenta figurinhas por um game, levou vantagem. Mas logo trocou o game por um celular estragado e ficou no prejuízo. Deu-se nesse momento a intervenção da ana- lista: "O que ganha quando perde?".

A partir daí começou a ser colocado algo da relação do adolescente com as meninas. $\mathrm{O}$ adolescente relatou um passeio que havia feito com colegas do colégio, mostrando assim que tinha dificuldade de estabelecer relações com seus pares. Os garotos o ficavam provocando, mas ele os ameaçava. Tinham medo dele, sabiam que cumpria o que falava. Ficou com as meninas porque não tinha amigos. Quando interrogado sobre o que era preciso para agradar as meninas, ele dizia que era preciso ter lábia, mas não sabia direito o que isso significava.

Notava-se que havia alguma questão da identificação com a virilidade e com o feminino. $\mathrm{O}$ jovem passou a falar da profissão que gostaria de seguir, a mesma do pai, de como era parecido com o pai: gostava de videogame, dormia tarde como ele. Relatou a doença do pai, a preocupação de que ele morresse, já que o pai era a coisa mais importante de sua vida. Também se perguntou sobre as meninas, como era ter lábia, do que elas gostavam, o que queria uma mulher.

Concomitantemente a essas inquietações, começou a interrogar o que se ocorria quando realizava as ações descritas acima: "Eu não sei o que acontece comigo, quando vi já fiz". As ações passaram a dar lugar a atitudes que visavam o seu futuro. Ele melhorou nos estudos e passou a se dedicar a cursos profissionalizantes. Iniciou um namoro e estava bastante empolgado com o relacionamento. 
Por fim, rompeu o namoro, o lhe que trouxe decepção com as meninas: "elas não diziam a verdade". Mais uma vez a questão sobre o feminino se atualizava.

\section{A inconsistência do Outro, o acting out e a passagem ao ato em Lacan}

A adolescência é um tempo lógico de colocação em jogo da subjetividade. A partir do encontro com o real da sexualidade é introduzido o sexual no corpo e a interdição que o social coloca ao exercício deste. Trata-se de um processo subjetivo que implica uma retomada da posição em relação ao Outro, que, por sua vez, mostra-se inconsistente, na medida em que há uma falta no Outro, dada pelo real da sexualidade (Forget, 2009).

No início do tratamento nada que se referisse a uma angústia em relação ao encontro com o real da sexualidade se colocava. Havia apenas as queixas escolares e dos pais. Essas queixas poderiam ser resumidas aos maus comportamentos na escola e às fugas. A fuga trouxe aos pais uma grande preocupação, um mal-estar em relação ao que se passava com o adolescente, denotando que havia um sofrimento, que não sabiam qual era, que, somado ao comportamento na escola, motivou a busca de tratamento.

$\mathrm{Na}$ análise que Lacan faz do acting out, este é sempre contraposto à pas- sagem ao ato. Lacan (2005) se utiliza de dois casos de Freud, as análises de duas adolescentes que se encontravam, no momento, confrontadas com o real da sexualidade e com questões relacionadas à sua posição em relação à partilha dos sexos: a jovem homossexual (Freud, 1922/1980a) e Dora (Freud, 1905/1980b). No primeiro caso, todo o avanço da jovem em relação à dama cortesã, os passeios próximos ao escritório de seu pai, eram da ordem do acting out, enquanto que o deixar cair da ponte era do registro da passagem ao ato. No caso de Dora, a bofetada dada por ela no Sr. K era uma passagem ao ato e, por outro lado, o comportamento paradoxal entre ela, seu pai e os K é considerado acting out. Também, no caso Dora, havia outro acting out, a carta de despedida que Dora deixa à mostra para que os pais encontrem. Nesses dois casos, o acting out, a carta de despedida no caso de Dora, e a passagem ao ato, no caso da jovem homossexual, tiveram a função de levar essas duas adolescentes à análise.

No caso relatado, os maus comportamentos e as fugas que incomodavam tanto a escola quanto os pais acabaram por encaminhar o adolescente para tratamento. No entanto, a demanda dirigida à analista, tanto por parte da escola quanto por parte dos pais, foi uma demanda de adaptação, enquanto o adolescente incomodavase muito pouco em relação àquilo de que uns e outros se queixavam.

Com base nos elementos in- 
troduzidos por Lacan, pretende-se sustentar que, onde o real do sexo emergia era abordado pelo adolescente por meio do ato. Esse real que emergia marcava a falta de um significante no Outro, a inconsistência do Outro e convocava o sujeito a se situar diante da castração, do desejo. A estruturação do desejo está situada na trama da relação edípica. Por isso, quando o sujeito se questiona sobre a falta do Outro, ele se coloca numa posição particular em face do enigma do desejo da mãe.

Percebe-se que o pai possuía atributos fálicos suficientes para constituir-se em um suporte identificatório. No entanto, a função paterna não era muito clara no discurso da mãe e na posição que o pai ocupava no desejo da mãe. Assim, dificultava a transmissão da castração e deixava o adolescente em um estado de suspensão quanto à identificação paterna. Ainda reforçando esse ponto, notava-se essa suposta preferência que a mãe dedicava ao adolescente em compensação a uma injustiça por parte do pai. A identificação com o pai não se transmitindo adia o confronto do sujeito com o complexo de castração, deixando-o no complexo de Édipo, fixado ao recurso da identificação com o falo materno, que falta à mãe. Caracteriza-se o momento do assujeitamento, na medida em que está assujeitado aos caprichos daquele de quem depende, posição angustiante, mas estrutural. $\mathrm{O}$ adolescente está cativo, em razão de se manter em um não se deparar com a castração da mãe e, portanto, não supor um para além do desejo da mãe, o que o coloca como objeto desta. Muitas das queixas que se evidenciam nesse caso podem ser supostas a partir dessa posição.

Uma dessas queixas seria a dificuldade de aprendizagem. O adolescente referia-se a uma dificuldade de se ater ao conteúdo escolar, apesar de ficar evidente que não havia nenhum déficit cognitivo. Essa dificuldade se inseria numa inibição intelectual. Não se deparando com a castração da mãe, havia um não querer saber sobre a falta, o que remete aos "Três ensaios sobre a teoria da sexualidade" (1905/1980c), em que Freud afirma que toda a reflexão intelectual da criança sobre "de onde vêm os bebês" condiciona-se ao saber sobre o que funda o desejo no inconsciente, o desejo do Outro. Trata-se do saber sobre a falta, sobre a castração. O progresso da trajetória investigativa da criança tende a ser inibido por uma renúncia do sujeito a saber sobre a castração.

Pode-se dizer que o adolescente, em razão dessa dificuldade em se deparar com o real da castração, sexualizou a função do saber, mantendo-se no não saber para não se deparar com a castração. 
Além das dificuldades escolares, suas ações também dizem algo dessa posição subjetiva em que se encontrava.

Os maus comportamentos que se apresentavam na escola denotavam que o objeto tinha um lugar particular para o adolescente. Tratava-se de ser o falo, o objeto que faltava à mãe, dando ao adolescente uma posição particular de objeto do Outro, o que dava coerência ao seu eu, pela via da identificação imaginária, e não deixava de trazer certa satisfação, que fazia calar o desejo.

Por estar identificado a esse objeto que completava o Outro, protegia para que a falta não aparecesse no Outro. Cristalizava-se uma resposta alienada diante do desejo do Outro, que o mantinha na posição de objeto e remetia a certos enunciados em que ficava patente uma impotência diante do Outro, já que este era totalizante e não permitia a falta, como: "Sou hiperativo", "Não consigo". Apesar de se manter nessa posição imaginária, havia um mal-estar. Assim, iniciou-se uma série de entrevistas que tinham como direção que essa resposta em ato se tornasse pergunta.

Estando identificado com o objeto, este não estava latente, colocava-se em ato, como acting out. Para Lacan (2005), o acting out é uma das operações em que o sujeito se relaciona com o objeto a, com a falta do Outro, que institui uma perda de objeto; é uma demonstra, ção de um desejo desconhecido que deixa transparecer o objeto $a$. $\mathrm{O}$ adolescente não podia dizer quase nada, apenas mostrava, em ato, uma cena onde o objeto a se mostrava de forma enigmática.

Nas frases "Meu pai sempre acha que minha irmã não faz nada, tudo fui eu...", "Tudo o que acontece na escola de errado fui eu...", o adolescente recebia uma mensagem do Outro sob a forma invertida. Essas mensagens, apesar de o enunciado consciente se inscrever numa repreensão, podiam fazer supor uma demanda do Outro, demanda de amor por excelência, que o adolescente respondia na via imaginária, o que permite ao sujeito falar "sou eu" e que no caso remetia ao "fui eu", enunciação que implicava seu eu no ato.

Se "fui eu", sua mãe o defendia, já que seu pai era injusto. As enunciações que se referiam aos atos colocavam em jogo algo da demanda na sua relação com a pulsão. Entrava em cena o pulsional entendido como a relação do sujeito com a demanda do Outro e que encontrará uma resposta para além do imaginário.

Tomar o mau comportamento como acting out é pôr em cena o que o inconsciente exibe, como uma mensagem endereçada ao Outro, encarnado num sujeito qualquer, não por meio de palavras, mas do 
ato. Essa mensagem é endereçada ao Outro barrado, ou seja, não ao Outro materno. Aqui se delineia algo que escapa à demanda de amor e convoca a falta. Assim, ao mesmo tempo em que o mau comportamento é uma resposta que permite ao adolescente permanecer na posição de ser o objeto da falta do Outro, também convoca o Outro barrado, aquele que não é consistente, é uma mensagem dirigida a este Outro, indicando o objeto a, enquanto causa do desejo.

Sabe-se que a passagem do complexo de Édipo para o complexo de castração é a chave da humanização da sexualidade e da assunção da função de desejo enquanto causa. Para que essa passagem seja bem-sucedida, para que o sujeito tenha acesso à significação simbólica do falo é preciso que a identificação ao falo materno falhe, preservando a incompletude do sujeito feminino. Esse processo permite que o sujeito se volte para o pai, para a partir daí portar as insígnias identificatórias e poder se colocar diante do feminino, da falta e, assim, assumir seu desejo.

O adolescente encontrava-se na busca de uma saída do Édipo. Para tanto era preciso fazer do falo da mãe um objeto perdido, para ter acesso ao falo simbólico. A análise buscou promover um laço com a castração do Outro, com o desejo do Outro. Quando o adolescente trouxe as trocas que fazia e em que ficava no prejuízo, ele pode ter acesso ao que ganhava quando perdia. De forma a possibilitar uma perda da posição de objeto em que se encontrava, para ter acesso a um para além da mãe, o que permitiu o acesso ao falo simbólico e às identificações simbólicas, situando-se diante do real da sexualidade.

Nesse momento algo da consistência do Outro foi abalada, o que se apresentou por meio do questionamento sobre as mulheres. O sujeito se deparou com o desejo do Outro, reconheceu um desejo para além da demanda que situava no primeiro Outro a quem dirigia sua demanda, a mãe.

Quando a castração no Outro se manifesta, introduz-se o complexo de castração. A castração será inicialmente encontrada no Outro. Só se deparando com a inconsistência do Outro foi possível ao adolescente subjetivar a metáfora paterna que modifica o desejo como desejo do Outro. Esse abalo na consistência do Outro também pode acontecer na medida em que se colocou em cena a possibilidade da morte do Outro. O pai ficou doente e nesse ponto surgiu a angústia, vislumbrando a proximidade da 
falta da falta. Assim, o adolescente pode subjetivar o pai morto, como pai simbólico, arriscar sair da posição de objeto para a posição de sujeito causado pelo objeto.

A castração no Outro se dá pelo significante do falo que barra o Outro, é esse significante que introduz uma divisão do gozo. Por um lado, proíbe o gozo infinito, o do pai da horda, e por outro lado permite o gozo fálico. É graças à castração que o registro do gozo sexual é aberto. A realização de um desejo implica a castração.

É próprio do tempo lógico da adolescência deparar com a inconsistência do Outro. Será em razão do abalo na consistência do Outro que o adolescente poderá perguntar: Che vuoi? O que o Outro quer de mim? O que pode conduzir ao caminho de seu próprio desejo. Porém, quando essa consistência foi abalada, a primeira resposta que o paciente encontrou foi da ordem da identificação com o pai. Passou a portar as insígnias do pai, como roupas, gostos, projetos para o futuro. Essa posição que remetia ao ideal do eu marcou a alienação do sujeito tanto na imagem quanto no significante e apontava, também, para a unidade do eu. Mesmo que aqui se ultrapassasse a reposta imaginária, na medida em que comportava as insígnias paternas, ainda se buscava suturar a falta do Outro.

Com essa resposta no nível do ideal, fica evidente que o pai é uma função simbólica crucial na adolescência, já que o adolescente faz um 
apelo ao pai na tentativa de dar conta do impacto do gozo que o invade. Mas o pai não responde às questões cruciais do sujeito. Tem algo que escapa, e é nessa medida que não se trata na análise de apostar na dissolução do complexo de Édipo, mas nesse algo que escapa.

Outra resposta possível do sujeito diante da falta de significante no Outro, como modo de defesa contra a castração, é a fantasia. $\mathrm{Na}$ fantasia há uma sujeição originária do sujeito ao Outro, mas aqui, a via principal para essa alienação não é o amor, mas a falta no Outro. Na notação que Lacan (1999) con-

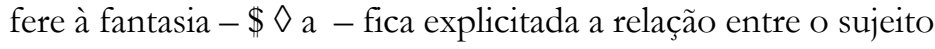
barrado, dividido pelo significante que o constitui e o objeto a, objeto inapreensível do desejo, que se refere a um vazio no campo do Outro. É a partir dessa lacuna que o sujeito constrói sua fantasia que serve de tela protetora para mediar o encontro faltoso com o real, é uma tentativa de resgatar sem sucesso a completude perdida.

Tendo como referência a fantasia, retomam-se as fugas. Note-se que o adolescente tinha muito pouco a falar delas, apenas enunciando "Não sei o que passava pela minha cabeça", como um momento de apagamento. Essas fugas podem ser pensadas como sendo do registro da passagem ao ato, como uma tentativa de sair de cena como uma resposta ao insuportável. O que é diferente de enviar uma mensagem de apelo ao Outro, já que se trata de uma forma radical de se separar dele. Diante de algo insuportável na relação com o Outro, das cobranças por um bom comportamento e da decepção, a única resposta possível foi subtrair-se do registro do simbólico para colocar-se no lugar do real; projetou-se para fora da cena. O sujeito aí não é mais um significante que se representa por meio da conexão com outro significante, mas é aquilo que do sujeito escapa ao simbólico, identificado com o objeto a.

\section{Ética e direção de tratamento}

Diante da inconsistência do Outro, o adolescente pode inscrever diversas formas de dar resposta ao insuportável da falta: seja como objeto do desejo do Outro, numa resposta imaginária; 
seja no nível do ideal do eu, na ordem simbólica, porém ainda alienada à demanda de amor e às insígnias paternas; seja na fantasia, suturando o Outro, não mais pela via do amor, mas pela via da falta. Entende-se que essas formas de resposta dadas pelo adolescente tomaram a forma do ato, seja como acting out ou como passagem ao ato. No primeiro momento, o adolescente estava na posição de objeto do desejo da mãe. Por ser neurótico já havia se deparado com a castração do Outro, mas buscava, por esta posição, não inscrever a falta. Tem-se a inibição intelectual como forma de não querer saber dessa falta, e o mau comportamento como acting out, numa resposta alienada à demanda do Outro, que se inscreve na frase "Meu pai sempre acha que minha irmã não faz nada, tudo fui eu...". Por essa via, no entanto, visa convocar o Outro barrado, na medida em que coloca em cena um desejo desconhecido, o objeto a.

Em um segundo momento, a consistência do Outro é abalada, o pai podendo cumprir sua função de transmitir os significantes, as insígnias e uma forma de se posicionar diante do feminino. A normalização do desejo dada pelo Nome-do-Pai, na medida em que interdita um gozo proibido, fornece as vias ao desejo. Mas do lado do pai, também se inscreve a inconsistência do Outro, já que este como personagem manco (Lacan,1997) interdita o gozo absoluto, desde sempre impossível. O lugar do Outro é vazado. Se nada mais há senão a falta, o Outro se esvai, não há garantia, algo escapa, os significantes não dão conta da questão do sujeito: "O que quer uma mulher?”, pergunta que deixa em evidência a falta e a dificuldade de se situar diante dela.

Mais uma vez, o sujeito encontra no ato, agora na forma da passagem ao ato, uma saída possível. Assim, diante do insuportável da falta do Outro, evade da cena, vaga pela cidade sem que qualquer significante venha a seu encontro.

Como se trata, neste artigo, de uma discussão clínica e esta sempre implica o analista como aquele que conduz a direção de tratamento, é válido resgatar os impasses transferenciais que surgiram. Os atos aqui evocados constituíram para esse adolescente a via possível de entrada em análise, isso em consonância com o que Lacan fala do acting out como um apelo ao Outro. Porém, na medida em que a analista se coloca, no primeiro momento, na posição de querer o bem do sujeito, responde pelo seu ser e não pela falta-a-ser, o que remeteria à irredutibilidade da falta e do desejo. Os atos que continuam a acontecer, que antes do início das entrevistas eram direcionados aos pais, passam a também ser direcionados à analista. Com isto, tinha-se um obstáculo ao trabalho, a verdade do sujeito era encoberta. Dessa forma, estes asos que persistiam durante o início das entrevistas na transferência eram a via em direção à verdade, enquanto, fora 
da análise, reafirmavam a alienação do adolescente a uma posição.

Lacan (1997), em O seminário 7: a ética da psicanálise, 1959-1960, afirma que o bem pode nos desencaminhar, na medida em que a dimensão do bem levanta uma barreira na via do desejo. Um repúdio radical de certo ideal do bem é necessário para se apreender a via em que se desenvolve a experiência analítica. Inclui a experiência analítica no campo do real, aí entendido como um resto que escapa a qualquer representação e que irá demarcar uma posição ética.

Dessa forma, só pela via da enunciação a travessia do ato foi possível, de forma a conduzir o sujeito nas vias do objeto a, enquanto causa do desejo. Inseriu-se o ato num contexto ético em contraposição à noção psicologizante sobre a tendência a atuações no comportamento do adolescente. Para tanto, foi necessário que a analista não operasse a partir de significações prontas, mas a partir da interpretação da enunciação, sustentando-se como objeto a, objeto causa do desejo. A interpretação refere-se mais a uma pontuação do discurso do que a um preenchimento do sentido. Não se trata de condenar ou desejar abolir o ato, mas o analista deve ajudar o paciente a bem dizer o seu ato e a reconhecer que seu ato diz respeito ao objeto a.

Assim, a análise permitiu que as diferentes respostas dadas ao ponto de insuportável da estrutura, à falta como tal, à inconsistência do Ouł tro - seja por meio da identificação 
imaginária, do acting out, da identificação com o pai ou na passagem ao ato - fossem abaladas. Respostas que o mantinham numa posição particular que implicava uma satisfação, sua alienação ao Outro, e não permitia a apropriação de seu desejo. Quando o adolescente sai do lado das respostas e pode formular as seguintes interrogações: "Eu não sei o que acontece comigo, quando vi já fiz" e "Elas não diziam a verdade", ele pode sustentar as perguntas sobre o enigma do desejo do Outro e pode ir à via do seu desejo.

Essa direção permite escutar, para além do transtorno, algo que implica aquele que fala em um mal-estar, que está para além do mal causado no social, mas remete à falta e àquilo que essa falta mobiliza de resposta possível para cada sujeito.

THE ADOLESCENT AND THE INCONSISTENCE OF THE OTHER: ARGUMENT ABOUT THE DIRECTION OF A CASE HANDLING, FROM A CASE STUDY

\section{Abstract \\ A discussion of a case study prioratizing something that shows in adolescents like mishehavior, and the psychiatry names it a perturbation of conduct. But here, will concern to an irrepressible, disruptive impulsive action, that approaches of the acting out, and the passage to the act described by Lacan (1962-1963) Seminary 10: the anguish. With this argument will be possible to affirm that these actions are answers facing the inconsistence of the Other, and propose a direction of handling, for these cases.}

Index terms: adolescence; acting out; passage to the act; lacanian psychoanalysis.

EL ADOLESCENTE YLA INCONSISTENCLA DEL OTRO:DEBATE SOBRE LA ORIENTACIÓN DEL TRATAMIENTO DE UN CASO CLÍNICO

\section{REsÚMEN}

Se discute un caso clínico dándole prioridad a algo que se manifiesta en los adolescentes como una mala conducta y que en la psiquiatría se llama trastorno de conducta. Pero aqui debe hacer referência a una acción impulsiva, incontrolable, iterrumpible, que está cerca de acting outy del pasaje al acto, descritos por Lacan (1962-1963) en el Seminario 10: angustia. Con este bilo, se puede decir que estas acciones son respuestas a la inconsistencia del Otro y proponer una dirección para el tratamiento de estos casos.

Palabras clave: adolescencia; el pasaje al acto; el acting out; el psicoanálisis lacaniano.

\section{REFERÊNCIAS}

Forget, J.-M.. (2009). Perversidade e perversão na adolescência. In J-M Forget, Adolescente, sexo e morte. Porto Alegre, RS: CMC Editora.

Freud, S. (1980a). A psicogênese de um caso de homossexualismo numa mulher. In S. Freud, Edição standard brasileira das obras psicológicas completas de Sigmund 
Freud (J. Salomão, trad., Vol. 18, pp. ??-??). Rio de Janeiro: Imago. (Trabalho original publicado em 1922)

Freud, S. (1980b). Fragmento da análise de um caso de histeria. In S., Edição standard brasileira das obras psicológicas completas de Sigmund Freud (J. Salomão, trad., Vol. 7, pp. ??-??). Rio de Janeiro: Imago. (Trabalho original publicado em 1905)

Freud, S. (1980c). Três ensaios sobre a teoria da sexualidade. . In S. Freud, Ediçāo standard brasileira das obras psicológicas completas de Sigmund Freud (J. Salomão, trad., Vol. 7, pp.??-??). Rio de Janeiro: Imago. (Trabalho original publicado em 1905)

Lacan, J. (1999). O seminário, livro 5: as formaçôes do inconsciente, 1957-1958. Rio de Janeiro: Jorge Zahar Editor.

Lacan, J. (1997). O seminário, livro 7: a ética da psicanálise, 1959-1960. Rio de Janeiro: Jorge Zahar Editor.

Lacan, J. (2005). O seminário, livro 10: a angústia, 1962-1963. Rio de Janeiro: Jorge Zahar Editor.

\section{NOTA}

1. Artigo referente a resultado de pesquisa realizada no Mestrado de Psicologia, linha de pesquisa de Psicologia Clínica, da Universidade Federal do Paraná.

mirstenzel@hotmail.com Rua Capitão Souza Franco, 945/32 80730-420 - Curitiba - PR - Brasil.

vdarriba@centroin.com.br Rua Marquês de São Vicente, 17/207 -

Bloco 2 22451-041 - Rio de Janeiro - RJ - Brasil.

Recebido em outubro/ 2012. Aceito em agosto/ 2013. 